\title{
1-D-ice flow modelling at EPICA Dome C and Dome Fuji, East Antarctica
}

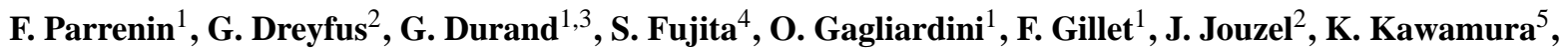 \\ N. Lhomme ${ }^{1}$, V. Masson-Delmotte ${ }^{2}$, C. Ritz ${ }^{1}$, J. Schwander ${ }^{6}$, H. Shoji ${ }^{7}$, R. Uemura ${ }^{4}$, O. Watanabe ${ }^{4}$, and N. Yoshida ${ }^{8}$ \\ ${ }^{1}$ Laboratoire de Glaciologie et Géophysique de l'Environnement, CNRS and Joseph Fourier University, Grenoble, France \\ ${ }^{2}$ Laboratoire des Sciences du Climat et de l'Environnement, Gif-Sur-Yvette, France \\ ${ }^{3}$ Niels Bohr Institute for Astronomy, Physics and Geophysics, Copenhagen, Denmark \\ ${ }^{4}$ National Institute of Polar Research, Research Organization of Information and Systems (ROIS), Tokyo, Japan \\ ${ }^{5}$ Center for Atmospheric and Oceanic Studies Graduate School of Science, Tohoku University, Sendai, Japan \\ ${ }^{6}$ Physics Institute, University of Bern, Switzerland \\ ${ }^{7}$ New Energy Resources Research Center, Kitami Institute of Technology, Kitami, Japan \\ ${ }^{8}$ Frontier Collaborative Research Center, Yokohama, Japan
}

Received: 11 December 2006 - Published in Clim. Past Discuss.: 16 January 2007

Revised: 10 May 2007 - Accepted: 14 May 2007 - Published: 1 June 2007

\begin{abstract}
One-dimensional (1-D) ice flow models are used to construct the age scales at the Dome $\mathrm{C}$ and Dome Fuji drilling sites (East Antarctica). The poorly constrained glaciological parameters at each site are recovered by fitting independent age markers identified within each core. We reconstruct past accumulation rates, that are larger than those modelled using the classical vapour saturation pressure relationship during glacial periods by up to a factor 1.5. During the Early Holocene, changes in reconstructed accumulation are not linearly related to changes in ice isotopic composition. A simple model of past elevation changes is developed and shows an amplitude variation of $110-120 \mathrm{~m}$ at both sites. We suggest that there is basal melting at Dome $\mathrm{C}(0.56 \pm 0.19 \mathrm{~mm} / \mathrm{yr})$. The reconstructed velocity profile is highly non-linear at both sites, which suggests complex ice flow effects. This induces a non-linear thinning function in both drilling sites, which is also characterized by bumps corresponding to variations in ice thickness with time.
\end{abstract}

\section{Introduction}

Ice cores drilled in central Greenland and Antarctica provide highly valuable records to reconstruct and understand Quaternary climates. Ice cores drilled at EPICA Dome C (hereafter EDC) and Dome Fuji (hereafter DF) provide two of the three longest ice core records available so far (EPICA com-

Correspondence to: F. Parrenin

(parrenin@ujf-grenoble.fr) munity members, 2004; Jouzel et al., 2007 ; Watanabe et al., 2003a), and reach respectively $\sim 800 \mathrm{kyr}$ and $\sim 330^{2} \mathrm{kyr} \mathrm{BP}$ (kilo years before 1950 A.D.). For the interpretation of these drillings, past ice flow modelling is needed. It allows one to estimate consistently 1) the age of the ice as a function of depth, 2) the conditions prevailing when the snow was deposited, e.g. accumulation rate and surface elevation, and 3) the total mechanical thinning of each ice layer. Conversely, data from deep drillings, like age markers, allow one to better constrain some ice flow parameters like basal conditions (melting and sliding), the velocity profiles, and the past accumulation variations.

Several modelling experiments were performed to derive age scales for deep ice cores. They use four different elements: 1) a mechanical model, 2) an accumulation model for the past, 3) some age markers along the core, and 4) an inverse method to constrain the poorly known parameters of the modelling from the age markers. The mechanical models used for these studies are simple kinematic models with prescribed geometry (surface and bedrock elevations, lateral flow divergence) and velocity profiles. Two analytical expressions have been used for the velocity profiles, either with a basal shear layer (Johnsen and Dansgaard, 1992), or based

\footnotetext{
${ }^{1}$ Jouzel, J., Masson-Delmotte, V., Cattani, O., et al.: Orbital and millennial Antarctic climate variability over the last 800000 years, submitted, 2007.

${ }^{2}$ The interpreted part of the Dome Fuji drilling is still far from the bedrock. Basal ice recovered during the second drilling operation may be much older.
}

Published by Copernicus Publications on behalf of the European Geosciences Union. 
on a polynomial approximation derived from the Shallow Ice Approximation (hereafter referred to as Lliboutry type velocity profile, Lliboutry, 1979). The variations in ice thickness and surface elevation are either neglected, or inferred from an ice sheet model, either a full 3-D thermo-mechanical one (Ritz et al., 2001), or a simplified version (Salamatin and Ritz, 1996). The accumulation rate is usually derived from the isotopic composition of the ice in the core, sometimes corrected for variations in the source isotopic composition and temperature (Vimeux et al., 2002). The inverse method used has often been an empirical trial and error method, except for recent studies where automatic and more objective Monte-Carlo methods were used (Parrenin et al., 2001; EPICA community members, 2004; Parrenin et al., 2004; Salamatin et al., 2004; Hondoh et al., 2004).

Current age scales at EDC and DF are limited in several ways. The EDC2 time scale for EDC (EPICA community members, 2004) is only valid for the last $740 \mathrm{kyr}$ because the older deuterium measurements needed for the accumulation were not available at the time of the construction of the time scale. The DF-FGT1.1 age scale for Dome Fuji (Watanabe et al., 2003a) did not consider the changes in isotopic composition and temperature of the source ocean water. Moreover, as explained below, the basal sliding and the changes in ice thickness were not properly taken into account for both sites.

This text describes the process of an improved modelling of ice flow at Dome C and Dome Fuji. We used a complete Lliboutry type velocity profile, taking into account basal conditions (melting and sliding). We also developed a simplified model of variations in ice thickness, which were fitted onto the results of a more complex 3-D thermo-mechanical model of Antarctica (Ritz et al., 2001). Our accumulation reconstruction takes into account the variations in source isotopic composition and temperature at DF. Our age markers are based on recent developments, in particular those based on the air content (Raynaud et al., 2007 ${ }^{3}$ ) and the $\mathrm{O}_{2} / \mathrm{N}_{2}$ (Kawamura et al., 2007) measurements. Our inverse method is based on a Monte-Carlo algorithm.

After examining the glaciological context at Dome Fuji and Dome C, we describe the 1-D mechanical model with prescribed velocity profile, and the elevation model, that are applied to both sites. The accumulation model is further described. The poorly constrained parameters of this glaciological model, such as the present-day accumulation rate, the glacial accumulation rate, basal melting and sliding, or the exponent of the vertical velocity profile, are tuned to fit independent age markers situated along the ice cores. The results of these inverse modelling experiments are then discussed, including the accumulation rates, the basal conditions, the velocity profiles, the variations in ice thickness and surface elevation, and the total thinning function. We then discuss

\footnotetext{
${ }^{3}$ Raynaud, D., Lipenkov, V., Lemieux-Dudon, B., et al.: The local insolation signature of air content in Antarctic ice: A new step toward an absolute dating of ice records, submitted, 2007.
}

how this modelling could be further improved in the coming years.

\section{A dating model for Dome $\mathrm{C}$ and Dome Fuji}

\subsection{Glaciological context at Dome C and Dome Fuji}

Rémy and Tabacco (2000) made a complete review of all the geographic data collected around Dome $\mathrm{C}$. The surface elevation data were determined using the ERS1 satellite data, and completed in the Dome C area with GPS measurements (Rémy et al., 1999). The bedrock elevation and internal layering data were acquired from airborne radar surveys (Tabacco et al., 1998). This data set was used to estimate the best location for the drilling site at the dome position $\left(75^{\circ} 06^{\prime} 06.35^{\prime \prime} \mathrm{S}, 123^{\circ} 23^{\prime} 42.76^{\prime \prime} \mathrm{E}\right)$, based on a minimal surface and bedrock slope and the regularity of the internal layers. The actual EPICA drilling site is located about $1400 \mathrm{~m}$ West of this topographic dome (Vittuari et al., 2004). The bedrock elevation data in the Dome $\mathrm{C}$ area were then refined with further measurements (Forieri et al., 2004). Surface velocity measurements confirmed that the horizontal velocity at the surface is less than a few $\mathrm{mm} / \mathrm{yr}$ at the topographic dome, while it is $15 \pm 10 \mathrm{~mm} / \mathrm{yr}$ at the EPICA drilling site (Vittuari et al., 2004). Surface elevation at Dome C is $3233 \mathrm{~m}$ a.s.l. (Tabacco et al., 1998) and the most accurate estimate of ice thickness is $3273 \pm 5 \mathrm{~m}^{4}$. At kilometric resolution, bedrock is relatively flat just around Dome $\mathrm{C}$ with variations always less than $100 \mathrm{~m}$ in a $5 \mathrm{~km}$ circle around the drilling site, and always less than $200 \mathrm{~m}$ in a $10 \mathrm{~km}$ circle. However, a large valley (the Concordia Trench) can be found $\sim 20 \mathrm{~km}$ East of Dome C, followed by a large elongated bedrock relief feature (the East Ridge, Forieri et al., 2004). Seismic experiments were conducted in the borehole and suggest the presence of water at the ice-bedrock interface or near this interface (the water might be readily permeating in the ground). Indeed, the reflection signal shows a small inverse phase reflection from near the expected bedrock level. Phase inversion occurs at transitions with decreasing acoustic impedance, which in this case is most likely an ice-water interface.

The location of the Dome Fuji drilling site is $\left(77^{\circ} 19^{\prime} \mathrm{S}\right.$; $39^{\circ} 40^{\prime} \mathrm{E}$ ), with a surface elevation of $3810 \mathrm{~m}$ a.s.l. and an ice thickness of $3028 \pm 15 \mathrm{~m}^{5}$, as estimated by radar measurements (Fujita et al., 2006). Based on the ERS-1 high resolution map of Antarctica compiled by Rémy et al. (1999), the

\footnotetext{
${ }^{4}$ This estimate is based on the total vertical depth of the ice core based on cable length corrected from hole inclination $(3256.7 \mathrm{~m})$, which agrees within a few meters with an estimate based on the total $\log$ depth of the core corrected for elastic and thermal expansion of ice and for hole inclination (3254.92 m). It is added to a $16 \mathrm{~m}$ layer of remaining ice as indicated by seismic experiments.

${ }^{5}$ Note that an outdated value of $3090 \mathrm{~m}$ has been used in several studies (Watanabe et al., 1999; Watanabe et al., 2003b; Hondoh et al., 2004).
} 
highest point on the dome plateau has been estimated $12 \mathrm{~km}$ West North West of the station (Fujita et al., 2006). The elevation of the station is, however, within $1 \mathrm{~m}$ of the highest point. The surface ice movement rate is less than several centimetres per year at Dome Fuji (Fujita et al., 2006). A bedrock elevation map has been constructed in the Dome Fuji area thanks to radar measurements (Watanabe et al., 2003b). This map shows larger bedrock relief than at Dome $\mathrm{C}$ in the surroundings of the drilling site, reaching $400 \mathrm{~m}$ at about $5 \mathrm{~km}$ from the drilling site.

\subsection{Ice flow model}

As discussed in the previous section, Dome $\mathrm{C}$ and Dome Fuji are situated very close to geographic domes of the ice sheet. Assuming these domes existed in the past, and neglecting the spatial variations in bedrock elevations, surface accumulation, and ice mechanical properties, we used a 1-D ice flow model to obtain age scales for EDC and DF. This is a simplified model with prescribed surface elevation and analytical vertical velocity profile, as has been usually used for other deep drilling sites like GRIP (Johnsen et al., 1995; Johnsen et al., 2001), Vostok (Parrenin et al., 2001; Parrenin et al., 2004), Dome Fuji (Watanabe et al., 2003a, 2003c; Hondoh et al., 2004) and Dome C (Schwander et al., 2001; EPICA community members, 2004). In this model, the vertical velocity $u_{\bar{z}}$ of the ice relative to the bedrock is expressed as:

$u_{\bar{z}}(\bar{z})=-\left[m+\left(a-\frac{\partial H}{\partial t}-m\right) \omega(\zeta)\right]$

where $B$ is bedrock elevation, $z$ is the vertical coordinate of the ice particle (oriented toward the top), $\bar{z}=z-B$ is the distance to the bedrock, $\zeta=\bar{z} / H$ is the non-dimensional vertical coordinate, $m$ is the melting rate at the base of the ice sheet, $a$ is the surface accumulation rate, $H$ is the ice thickness and $\frac{\partial H}{\partial t}$ is its temporal variation. The velocity field can equally be expressed in the non-dimensional coordinate (see Appendix 1). Note that $H$ and $z$ are expressed in ice equivalent, i.e. the firn is compressed into pure ice. At Dome $\mathrm{C}$ and Dome Fuji, this is done using the measured density profile in the firn. For practical reasons, we used the raw log depth as a real depth at both EDC and DF (i.e. no corrections were applied for the thermal and elastic expansion of the ice and for the hole inclination).

$\omega(\zeta)$, called the flux shape function (Parrenin et al., 2006), depends on the non-dimensional vertical coordinate and is the contribution of one sliding term and one deformation term:

$\omega(\zeta)=s \zeta+(1-s) \omega_{D}(\zeta)$ where $s$ is the sliding ratio ${ }^{6}$ and $\omega_{D}(\zeta)$ can be approximated by (Lliboutry, 1979):

$\omega_{D}(\zeta)=1-\frac{p+2}{p+1}(1-\zeta)+\frac{1}{p+1}(1-\zeta)^{p+2}$

where $p$ is a parameter for the vertical profile of deformation $\omega_{D}(\zeta)$.

Contrary to the formulation of the Dansgaard-Johnsen model (Johnsen, 1992) with a basal shear layer (see Appendix 1), also used by Watanabe et al. (2003c), this formulation is continuous. This profile of deformation has been previously used to interpret the Vostok (Ritz, 1989; Parrenin et al., 2001; Parrenin et al., 2004; Salamatin et al., 2004) and Dome Fuji ice cores (Hondoh et al., 2004), though it was expressed differently in those studies (see Appendix 1). Note also that Salamatin et al. (2004) and Hondoh et al. (2004) did not consider any basal melting in their models, and used only an approximation of the complete formulation (see Appendix 1).

Such a shape function was first introduced by Lliboutry (1979), who derived it by assuming a steady state, the Shallow Ice Approximation (SIA), isotropic ice following the Glen flow law, and by approximating the vertical temperature profile at the base of the ice sheet by a linear trend. He found:

$p=n-1+k G_{0} H$,

where $n$ is the exponent of Glen's law, $G_{0}$ is the vertical temperature gradient, and $k$ is given by:

$k=\frac{Q}{R T_{b}^{2}}$,

where $Q=60 \mathrm{~kJ} / \mathrm{mole}$ is an activation energy, $R=8.3145 \mathrm{~J} / \mathrm{mole} / \mathrm{K}$ is the perfect gas constant, and $T_{b}$ is the bottom temperature (in Kelvin). Note that other authors have used a value up to 2 times larger for the activation energy $Q$ (Lliboutry and Duval, 1985). The uncertainty in $Q$ is larger for higher temperatures, that is for basal ice, where the deformation is concentrated.

At Dome C, using $n=3, \quad T_{b}=270.2 \mathrm{~K}$, $G_{0}=2.162 \times 10^{-2} \mathrm{~K} / \mathrm{m}$, and $H=3266 \mathrm{~m}$, we find $p \simeq 9$. Tests with a full Stokes model confirm this approximated value very well (Gillet-Chaulet et al., 2006). Adding anisotropic behaviour for the ice as measured in the GRIP ice core fabrics (Thorsteinsson et al., 1997) in these conditions where the SIA applies increases shearing stresses and, in turn, ice fluidity, leading to more deformation in the bottom part and thus a greater exponent. Modelling experiments (Gillet-Chaulet, 2006) show an increase of the exponent by 1.4 , and we can thus say that the impact of anisotropy under these SIA conditions is small.

\footnotetext{
${ }^{6}$ Ratio of the basal horizontal velocity to the vertically averaged horizontal velocity. It is 0 for no sliding and 1 for full sliding.
} 
However, there are reasons why this theoretical value of $p$ may not be valid. First, as explained above, the activation energy $Q$ is not well constrained. Second, the SIA is not applicable at a dome, where the isochrone layers may arch up forming the so-called Raymond bumps (Raymond, 1983). However, radar profiles from the Dome C (Tabacco et al., 1998) and Dome Fuji (Fujita et al., 1999) areas, which show internal reflection layers, do not reveal any signs of anomalous vertical strain. Third, the SIA implies flat bedrock topography around the drilling site. This is not the case at Dome $\mathrm{C}$ and Dome Fuji. For example, if the drilling site is situated above a bedrock depression, we may reach, close to the bedrock, dead ice or at least slowly moving ice, as obtained by a smaller exponent with the analytical profile. Fourth, tests with a full Stokes model showed that the impact of the anisotropic behaviour of the ice in the cases when the SIA hypotheses are not respected can become very important.

For these reasons, the $p$ parameter of the velocity profile will not be prescribed, but optimally adjusted by an inverse method, so that the ice chronology fits some age markers (see Sect. 3). The smaller $p$, the more non-linear the vertical velocity profile. Still, we assume that the $p$ parameter is constant in time, that is to say we assume that the ice flow conditions at Dome $\mathrm{C}$ and Dome Fuji did not change significantly in the past. For the same reason, we assumed that the sliding ratio $s$ is constant in time.

Given the small variations in basal temperature induced by changes in surface temperature and changes in ice thickness, basal melting is in general roughly constant in time. For this reason we assume $m$ to be constant in the following. The values of $p, m$ and $s$ will be optimally adjusted by the inverse method.

\subsection{Accumulation model}

Accumulation $A$ and temperature $T$ are deduced from the deuterium content of the ice extracted from the drill core, through the following relationships:

$$
\begin{aligned}
& A=A^{0} \exp \left(\beta \Delta \delta D_{\text {smo }}\right) \\
& T=T^{0}+\alpha \Delta \delta D_{\text {cor }}
\end{aligned}
$$

where $A^{0}$ and $T^{0}$ are surface accumulation and temperature for a reference deuterium content of $-396.5 \%$ (roughly corresponding to the present value). $\Delta \delta D_{\text {smo }}$ is a $50-\mathrm{yr}$ smoothed version of $\Delta \delta D_{\text {cor }}$ because the accumulation rate $A$ is supposed to be related to the isotope content of the deposited snow only over a certain time interval. Several other authors also used this simple exponential relationship (Watanabe et al., 2003c; Hondoh et al., 2004; Salamatin et al., 2004), while some others used a relationship based on the saturation vapor pressure (Schwander et al., 2001; Watanabe et al., 2003a; EPICA community members, 2004; Parrenin et al., 2004), and on a linear relationship between the surface temperature and the temperature when and where snow formed (named condensation temperature). Note however that all formulations give the same results within $1 \%$ after adjustment of the $\beta$ coefficient.

$\Delta \delta D_{\text {cor }}$ is the deviation from the present-day value of the deuterium content of the ice isotope corrected for the variations in isotope and temperature at the source of the air masses, given by (following Vimeux et al. (EPSL, 2002) notations):

$\Delta \delta D_{\text {cor }}=\Delta \delta D+\frac{\gamma_{\text {source }}}{\beta_{\text {source }}} \Delta d+\frac{\gamma_{\text {source }} \beta_{m}-\beta_{\text {source }} \gamma_{m}}{\beta_{\text {source }}} \Delta \delta^{18} \mathrm{O}_{m}$,

where $\Delta \delta D, \Delta d$ and $\Delta \delta^{18} \mathrm{O}_{m}$ are deviations from the present-day values of, respectively, the deuterium content of the ice, the deuterium excess content of the ice, and the oxygen-18 content of oceanic water, as reconstructed by Bintanja et al. (2005), based on the exhaustive LR04 oceanic stack (Lisiecki and Raymo, 2005). Because these two curves are not on the same time scales, we synchronised them by correlating the Northern hemisphere surface temperature reconstruction of Bintanja et al. (2005) with the Dome Fuji and Dome C ice isotopic records. The coefficients of Eq. (8) have been inferred at both sites using a simple Rayleigh-based model, constrained with present-day surface data on the trajectories of air masses (Stenni et al., 2003; Kawamura et al., $2007^{4}$ ). For Dome C, the excess record is not yet available all along the core, and thus only variations in isotope at the source have been corrected (i.e., we used $\gamma_{\text {source }}=0$ ).

For Dome Fuji, Watanabe et al. (2003a, c) did not use any source correction for the isotope-accumulation relationship, while Hondoh et al. (2004) only used a simple correction of the source variations in oceanic composition, based on the sea level reconstruction by Bassinot et al. (1994). For Dome C, an oceanic correction based on a scaled version of Bassinot's isotopic curve was used in EDC1 and EDC2 (Schwander et al., 2001; EPICA community members, 2004).

We chose $\alpha=1 / 6.04 \mathrm{~J} / \mathrm{K}$ from present-day surface measurements between Dumont d'Urville and Dome C (Lorius and Merlivat, 1977). For Dome C, we chose $T^{0}=217.5 \mathrm{~K}$, from a best fit of modelled firn temperatures with data (J.-M. Barnola, private communication). $T^{0}=215.85 \mathrm{~K}$ for Dome Fuji, based on the average temperature in snow at $10 \mathrm{~m}$ depth (Fujita et al., 1998).

$A^{0}$ is reconstructed by the inverse method (see below), thanks in particular to shallow age markers. $\beta$ influences the glacial-interglacial amplitude of accumulation changes. A theoretical value for $\beta$ is 0.0102 , using the above value of $\alpha=1 / 6.04 \mathrm{~K} / \%$, using a factor of 0.63 for the surface temperature/inversion temperature relationship (Connolley, 1996) and assuming precipitation follows the saturation vapour pressure. In practice, these values are not well constrained, and we are not certain that they are valid for the past. For this 
reason we do not prescribe the value of $\beta$, and we estimate it with the inverse method.

This reconstruction of the snow accumulation rate from the isotopic content of the ice holds for the part of the vertical profile where ice has been drilled. For the bottom $\sim 500 \mathrm{~m}$ at Dome Fuji, however, there is no isotopic data on which to base our estimation. So we created a synthetic Antarctic isotopic record, based on the Dome $\mathrm{C}$ isotopic record on the EDC2 time scale (EPICA community members, 2004) for the last $740000 \mathrm{yrs}$, and then based on the Bintanja et al. (2005) temperature reconstruction. This synthetic record has then been transformed into a Dome Fuji synthetic isotopic record with a linear relationship.

\subsection{Algorithmic and numerical aspects}

Given a history of the various parameters of the model ( $m$, $s, a, H, p)$, the velocity field $u_{z}(t)$ at each time $t$ is defined. The ice particles along the deep drilling (in practice at Dome $\mathrm{C}$ every $0.55 \mathrm{~m}$ core segment and at Dome Fuji every meter) are then back-tracked from their present-day position to the surface with a Lagrangian scheme. The position $z-d z$ of an ice particle at time $t$ - $d t$ is deduced from its position $z$ and velocity $u_{z}(t)$ at time $t$ through:

$d z=u_{z} d t$

The age $X$, the initial accumulation rate $a$ and ice thickness $H$ of every ice particle are obtained when this particle crosses the surface. We call the age obtained by this method the "pure-Lagrangian age".

The age can be obtained by an alternative method, using the thinning function $T(z)$ along the vertical profile, which is the ratio of an ice layer thickness to its initial thickness at the surface. This thinning function can be computed by integrating along the particle trajectories the vertical compression $\frac{\partial u_{z}}{\partial z}$, which, from Eq. (1), is equal to:

$\dot{\varepsilon}_{z z}=\frac{\partial u_{z}}{\partial z}=-\frac{1}{H}\left(a-\frac{\partial H}{\partial t}-m\right) \omega^{\prime}(\zeta)$,

with:

$\omega^{\prime}(\zeta)=s+(1-s) \omega_{D}^{\prime}(\zeta)$,

and:

$\omega_{D}^{\prime}(\zeta)=\frac{p+2}{p+1}\left[1-(1-\zeta)^{p+1}\right]$

The thickness $\Delta z(t-d t)$ of a layer at time $t$-dt is deduced from the thickness $\Delta z(t)$ at time $t$ through:

$\Delta z(t-d t)=\Delta z(t) \times\left(1+\dot{\varepsilon}_{z z} d t\right)$.

The age is then calculated by an integration from the surface of the inverse of the annual layer thickness:

$\operatorname{age}(z)=\int_{z}^{S} \frac{1}{T\left(z^{\prime}\right) a\left(z^{\prime}\right)} d z^{\prime}$.
We call this scheme the "Lagrangian-thinning Eulerianage scheme". In principle, these two ages should be equal, so that the remaining differences reflect different numerical approximations. For the "pure Lagrangian" scheme, there is only a discretization in time for the integration of the particle position, while for the "Lagrangian-thinning Eulerian-age scheme", there is a discretization in time for the integration of the thinning function and a discretization in space for the integration of the age. In practice for Dome $\mathrm{C}$, we take a $d t$ time step of $100 \mathrm{yr}$ and find a difference between these two ages always less than $0.5 \%$ of the age, which gives an estimate of the numerical errors of this model.

We note also a circularity in our dating model concerning the accumulation rate. Indeed, what we need is a scenario of accumulation as a function of time, while what we have is an estimation of the accumulation as a function of the depth in the deep drilling. We thus need a depth/age relationship for the deep drilling, which is what we are trying to estimate. We solve this problem by applying iterations on the age scale. We start with a preliminary age scale, assuming a linear thinning function varying between 0 at the bottom and 1 at the surface. We then apply our ice flow model and obtain a new age (either with the pure-Lagrangian scheme or with the Lagrangian-thinning Eulerian-age scheme). This new age make it possible to estimate a revised accumulation scenario, etc. We stop when the age has converged. In practice at Dome $\mathrm{C}$ and Dome Fuji, 5 iterations are sufficient.

\subsection{Estimation of ice thickness variations at Dome $\mathrm{C}$ and Dome Fuji}

The variations in the ice thickness actually depend on large scale processes, like the variations in surface temperature and accumulation on the Antarctic plateau, and the position of the grounding line far from the drilling site (Ritz et al., 2001). For EDC2, they were obtained from a 3-D model of Antarctica (Ritz et al., 2001). But there is the same kind of circularity problem here as described above. Indeed, the 3-D model needs as forcing a temporal history of accumulation and temperature, which are deduced from the EDC ice core and thus depends on its age scale. The term $a-\frac{\partial H}{\partial t}$ should be very smooth, because it represents the vertical velocity $u_{\bar{z}}$ of the particle at the surface. However, for EDC2, this term was not smooth because the terms $a$ (coming from the 1-D model) and $\frac{\partial H}{\partial t}$ (coming from the 3-D model) used different age scales, numerical resolutions, and accumulation reconstructions, which lead to unrealistic compressions, and an irregular thinning function.

It is not possible to apply one run of the 3-D model per run of the 1-D model because the 3-D model is far too expensive in computation time and we need to test thousands of dating scenarii in the context of the Monte Carlo inverse method (see below). It is why we developed a conceptual model of ice thickness variations (with very fast computation time) whose parameters are tuned to fit the results of the 
Table 1. Main characteristics of the Dome C and Dome Fuji drilling sites.

\begin{tabular}{lll}
\hline & Dome C & Dome Fuji \\
\hline Location of drilling site & $75^{\circ} 06^{\prime} 06.35^{\prime \prime} \mathrm{S} ; 123^{\circ} 23^{\prime} 42.76^{\prime \prime} \mathrm{E}$ & $77^{\circ} 19^{\prime} \mathrm{S} ; 39^{\circ} 40^{\prime} \mathrm{E}$ \\
\hline Surface elevation & $3233 \mathrm{~m} \mathrm{a.s.1.}$ & $3810 \mathrm{~m} \mathrm{a.s.l.}$ \\
Distance to the topographic dome & $1.4 \mathrm{~km}$ & $12 \mathrm{~km}$ \\
Ice thickness & $3273 \pm 5 \mathrm{~m}$ & $3028 \pm 15 \mathrm{~m}$ \\
Surface accumulation rate & $2.84 \mathrm{~cm}$-of-ice $/ \mathrm{yr}$ & $2.99 \mathrm{~cm}$-of-ice $/ \mathrm{yr}$ \\
Mean surface snow temperature & $218.5 \mathrm{~K}$ & $215.85 \mathrm{~K}$ \\
\hline
\end{tabular}

Table 2. Parameters of the simplified model of elevation variations for Dome C and Dome Fuji.

\begin{tabular}{lcccccc}
\hline site & $B_{0}(\mathrm{~m})$ & $k\left(\mathrm{~m} \mathrm{yr}^{-1}\right)$ & $k_{H}\left(\mathrm{yr}^{-1}\right)$ & $k_{S}\left(\mathrm{yr}^{-1}\right)$ & $k_{B}$ & $\tau_{B}(\mathrm{yr})$ \\
\hline Dome C & 916.5 & 0.3917 & $6.114 \times 10^{-4}$ & $-7.018 \times 10^{-4}$ & 3.8 & 3000 \\
Dome Fuji & 1667 & 1.3945 & $8.292 \times 10^{-4}$ & $-9.916 \times 10^{-4}$ & 3.8 & 3000 \\
\hline
\end{tabular}

large scale 3-D model on a standard experiment. This model is a simple linear perturbation model, where the vertical velocity of ice at surface $a-\frac{\partial H}{\partial t}$ is written:

$a-\frac{\partial H}{\partial t}=k+k_{H} H+k_{S} S$,

and where the bedrock follows a simple relaxation law to an equilibrium:

$$
\frac{\partial B}{\partial t}=\frac{\left(B_{0}-H / k_{B}\right)-B}{\tau_{B}},
$$

where $B$ is the bedrock elevation, $S=B+H$ is the surface elevation of the ice sheet, and $k, k_{H}, k_{S}, k_{B}, B_{0}$, and $\tau_{B}$ are parameters. $B_{0}$ corresponds to a bedrock elevation without isostatic effect.

To constrain the values of these parameters, we used a 3-D thermo-mechanically coupled model (Ritz et al., 2001), with a temporal variation of surface accumulation rate given by the EDC2 chronology for Dome C (EPICA community members, 2004). Some other parameters of the model (e.g. spatial distribution of accumulation rate, geothermal heat flux, basal sliding) were tuned so that the stratigraphy is correctly simulated at Dome C and Dome Fuji (Lhomme, 2004). We also checked that our simplified model is still consistent with the 3 -D one when using a $20 \%$ reduced or increased amplitude of glacial-interglacial accumulation changes.

Then we tuned the values of the simple elevation model in two steps. First, the values $B_{0}, k_{B}$ and $\tau_{B}$ are tuned by a Monte Carlo method so that the bedrock elevation of the simple 1-D model optimally agrees with the bedrock elevation of the 3-D model. The ice thickness from the 3-D model is used for this first step. Then, to determine the values of $k, k_{H}, k_{S}$, $k_{B}$, we applied a linear regression of $a-\frac{\partial H}{\partial t}$ simulated by the 3-D model, with the values of $H$ and $S$.
The inferred values for these parameters at Dome $\mathrm{C}$ and Dome Fuji are given in Table 2. Figure 1 compares the ice thickness variations from the $3-\mathrm{D}$ and 1-D models. The maximum difference between both models is less than $25 \mathrm{~m}$, both for Dome Fuji and Dome C.

Among previous studies for Dome $\mathrm{C}$ and Dome Fuji, only EPICA community members (2004) and Hondoh et al. (2004) took into account changes in ice thickness. EPICA community members (2004), however, used elevations variations obtained from a 3-D thermo-mechanical model of Antarctica (Ritz et al., 2001), and this work thus suffers from the inconsistencies mentioned at the beginning of this section. The work by Hondoh et al. (2004) is also based on a simplified model of surface and bedrock elevations (Salamatin and Ritz, 1996), but this simplified model was not tuned onto a full 3-D thermo-mechanical model, but on a simplified 2-D version that does not account for the geometry of East Antarctica.

Note that the formulation of this simple model of elevation does not guarantee that the present-day ice thickness is compatible with the measured ice thickness $H_{0}$ for every accumulation scenario. For this reason we used only the temporal variations $\Delta H(t)=H(t)-H(t=0)$ of ice thickness from this model, and $H_{0}+\Delta H(t)$ is the ice thickness of the 1-D ice flow model used in Sect. 2.2. This temporal ice thickness scenario is in practice updated for each iteration of the dating loop defined at the end of previous section.

\section{Age markers and inverse method}

Five parameters of this glaciological dating model are poorly constrained: two accumulation parameters (the presentday accumulation rate, $A_{0}$, and $\beta$, related to the glacial- 

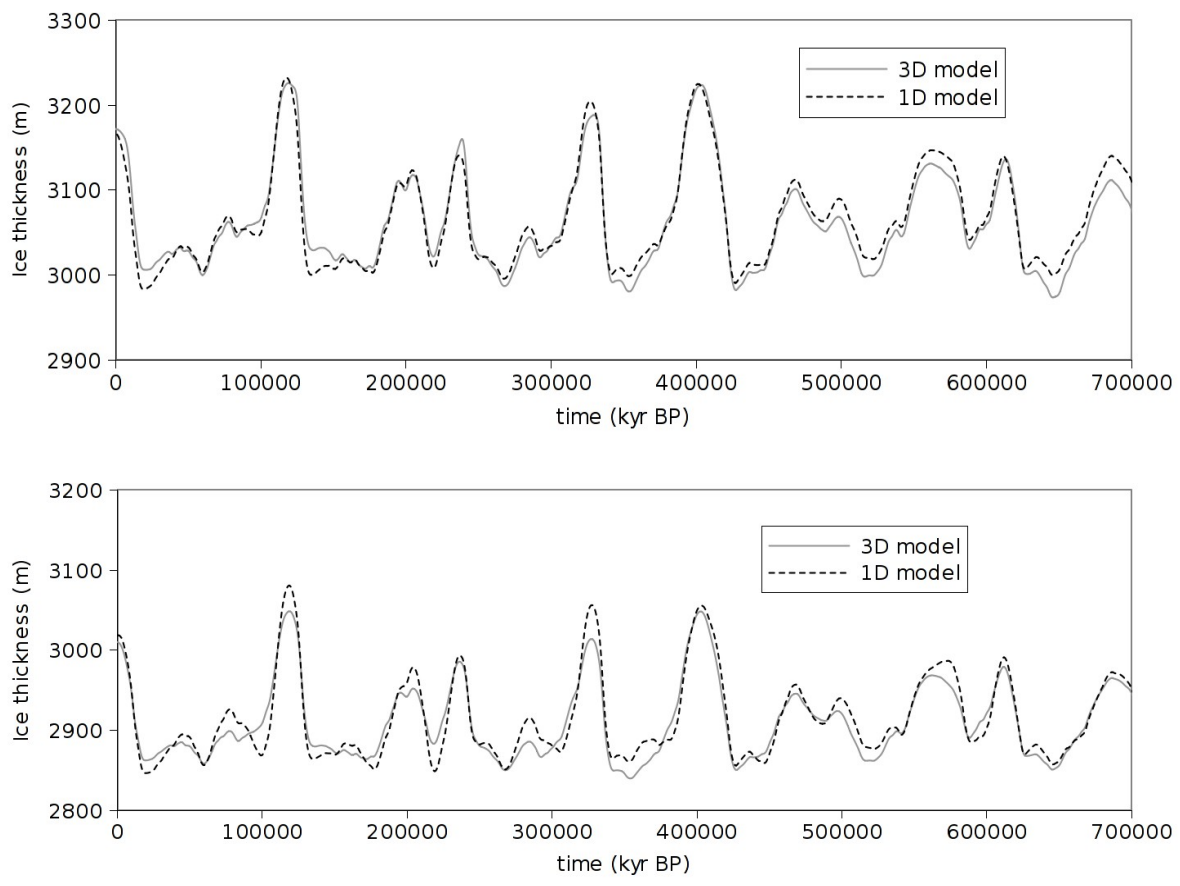

Fig. 1. Comparison of ice thickness variations from the 3D thermo-mechanical model and from the simple 1-D model, at Dome C (top) and at Dome Fuji (bottom).

interglacial amplitude of accumulation changes) and three flow parameters (the sliding ratio, $s$, the exponent of the deformation profile, $p$, and the basal melting rate, $m$ ). These parameters are tuned thanks to a priori information on the age at certain depths (so called age markers). The inverse procedure has been described elsewhere (Parrenin et al., 2001; Parrenin et al., 2004). It is based on the Metropolis-Hastings algorithm, and produces not only a more likely age scale (the one in optimal agreement with the age markers) but also a probability density for each model parameter, providing a confidence interval on the reconstructions.

Similar tuning procedures to age markers have been used in previous studies, either a manual one (Watanabe et al., 2003c), or an automatic and objective one (Parrenin et al., 2001; Schwander et al., 2001; Watanabe et al., 2003a; EPICA community members, 2004; Hondoh et al., 2004; Parrenin et al., 2004; Salamatin et al., 2004).

One might be tempted to use as many available age markers as possible, to use the conjunction of all available information, and to obtain a really optimal estimate of the age scale and of the glaciological parameters. This would be the case with a perfect model, that is to say a model that, given the exact values of these five poorly constrained parameters described above, would evaluate without error the age scale. This is, however, not the case: apart from these poorly constrained parameters, the model still contains unidentified sources of uncertainties. For example, the accumulation rate $a$ may not be simply related to the isotopic content of the ice. Or, the Dome $\mathrm{C}$ ice may not originate from the Dome $\mathrm{C}$ site, because of dome movements in the past, etc. Thus, if we use too many age markers in one part (e.g. the Holocene), the model may be over-tuned in this part and may decrease in precision for other time periods. Using all available age markers would thus over tune our parameters. This is also why we systematically multiply by a factor of 2 the confidence interval of the age markers: a 2 sigma error bar is taken as 1 sigma error bar in the inverse method. The choice of the age markers contains thus, at this stage, a part of subjectivity. This point of view differs from that of other authors (Hondoh et al., 2004; Salamatin et al., 2004), who chose to use as many age markers as possible, and who did not take into account the possible dependence of the errors associated with those age markers. Our subjective elimination of some age markers is not fully satisfactory, though, and a study is underway to develop an inverse method that takes into account modelling uncertainties and avoids this subjective choice.

The age markers used for Dome $\mathrm{C}$ are described in more detail in the companion paper Parrenin et al. (2007), and are summarized in Table 3. They contain the El Chichon horizon (691 yr BP) at $38.12 \mathrm{~m}$ depth (Castellano et al., 2005), two age markers coming from the synchronization with the NGRIP/GICC05 age scale (Rasmussen et al., 2006) or with the INTCAL04 age scale through the Beryllium 10 record (Raisbeck et al., 1998; Beer et al., personal communication), two age markers during the last deglaciation synchronized with the NGRIP/GICC05 age scale through the 
Table 3. Age markers used to tune poorly-known glaciological parameters at Dome C. Depth refers to the official log depth.

\begin{tabular}{lccc}
\hline age marker & depth $(\mathrm{m})$ & age $(\mathrm{kyr} \mathrm{BP})$ & Used error bar (kyr) \\
\hline $\mathrm{El} \mathrm{Chichon?}$ & 38.12 & 0.691 & 0.005 \\
${ }^{10} \mathrm{Be} /{ }^{14} \mathrm{C}$ & 107.83 & 2.716 & 0.05 \\
${ }^{10} \mathrm{Be} /{ }^{14} \mathrm{C}$ & 181.12 & 5.280 & 0.05 \\
$\mathrm{YD} /$ Holocene (GICC05) & 361.5 & 11.65 & 0.18 \\
$\mathrm{~PB} / \mathrm{BO}(\mathrm{GICC05})$ & 427.2 & 15.0 & 0.24 \\
${ }^{10} \mathrm{Be}$ peak & 740.08 & 41.2 & 1 \\
$\mathrm{Mt}$ Berlin ash layer & 1265.10 & 92.5 & 2 \\
term. II & 1698.91 & 130.1 & 2 \\
air content & 1082.34 & 70.6 & 4 \\
air content & 1484.59 & 109.4 & 4 \\
air content & 1838.09 & 147.6 & 4 \\
air content & 2019.73 & 185.3 & 4 \\
air content & 2230.71 & 227.3 & 4 \\
air content & 2387.95 & 270.4 & 4 \\
air content & 2503.74 & 313.4 & 4 \\
air content & 2620.23 & 352.4 & 4 \\
air content & 2692.69 & 390.5 & 4 \\
air content & 2789.58 & 431.4 & 4 \\
$18 \mathrm{O}_{\text {atm }}$ & 2998.96 & 578.6 & 6 \\
${ }^{18} \mathrm{O}_{\text {atm }}$ & 3035.41 & 622.1 & 6 \\
$\mathrm{~B}-\mathrm{M}$ reversal & 3165 & 785 & 20 \\
\hline
\end{tabular}

methane record, the well-known beryllium 10 peak due to the Laschamp magnetic event (Raisbeck et al., 2007) and dated with NGRIP/GICC05 (Andersen et al., 2006; Svensson et al., 2006); an ash layer from the Mt Berlin volcanoes dated at 92.5 kyr (Narcisi et al., 2006); an age of termination II based on comparison with dated sea level high stands and dated speleothems; 10 age markers coming from the comparison of air content with insolation (Raynaud et al., $2007^{3}$ ); 2 age markers from the comparison of oxygen-18 of air bubbles with insolation (Dreyfus et al., 2007) and finally the Brunhes-Matuyama magnetic reversal identified with the Beryllium 10 record (Raisbeck et al., 2006).

The age markers for Dome Fuji have been described in more detail in Kawamura et al. $\left(2007^{4}\right)$, and summarized in Table 4. They are comprised of one age marker during the ACR-Holocene transition by comparison to the EDML isotopic record synchronized onto the GICC05 age scale (Loulergue et al., 2007); the beryllium 10 peak, whose position has been estimated by a DC-DF synchronisation of the ice isotopes; the Mt Berlin volcanoes dated at 92.5 kyr (Narcisi et al., 2006); the timing of termination II, imported from the EDC one by deuterium- $\delta^{18} \mathrm{O}$ synchronisation; and 12 age markers from the DFO-2006 $\mathrm{O}_{2} / \mathrm{N}_{2}$ age scale (Kawamura et al., $2007^{4}$ ).

It is important to understand qualitatively how the resulting optimal age scale depends on the age markers used. The thinning function is well constrained for the upper several hundred meters. Thus, the $A_{0}$ parameter is constrained by the Holocene age markers, because the $\beta$ parameter has almost no impact (the isotopic content of ice is relatively constant over this period). Then, the $\beta$ parameter is constrained by the age of the ${ }^{10} \mathrm{Be}$ peak at $\sim 41 \mathrm{kyr}$ BP. Finally, the flow parameters $m, p$ and $s$ are constrained by all the orbital age markers. Since there are many more age markers than there are unknown flow parameters, the resulting age scale and parameter evaluation is relatively independent of the value of one particular age marker.

\section{Results and discussions}

The densities of probability of these five poorly-known parameters of the glaciological dating models reconstructed by the inverse method at Dome Fuji and Dome $\mathrm{C}$ are illustrated in Fig. 2. In what follows, we give numerical values for the most likely scenario, and confidence intervals $( \pm 2 \sigma$, noted between brackets). Modelling results for the most likely scenarios are given in the Supplementary Material (http://www. clim-past.net/3/243/2007/cp-3-243-2007-supplement.zip).

\subsection{Reconstruction of surface accumulation rates}

At Dome $\mathrm{C} A_{0}=2.841$ [2.840 \pm 0.028$] \mathrm{cm}$-of-ice/yr. It gives an average value of $2.793 \mathrm{~cm}$-of-ice/yr for recent millennia, and $2.849 \mathrm{~cm}$-of-ice/yr for the last $7 \mathrm{kyr}$. This last value is $2 \%$ below the value of $2.878 \mathrm{~cm}$-of-ice/yr inferred by Schwander et al. (2001) for the EDC1 age scale, by comparison to 
Table 4. Age markers used to tune poorly-known glaciological parameters at Dome Fuji. Depth refers to the official log depth.

\begin{tabular}{lccc}
\hline age marker & depth $(\mathrm{m})$ & age $(\mathrm{kyr} \mathrm{BP})$ & Used error bar $(\mathrm{kyr})$ \\
\hline ACR-Holocene transition & 371.0 & 12390 & 0.4 \\
$\mathrm{Be} 10$ peak & 791 & 41.2 & 1 \\
$\mathrm{O}_{2} / \mathrm{N}_{2}$ a.m. & 1261.93 & 81.85 & 4 \\
$\mathrm{Mt} \mathrm{Berlin} \mathrm{ash} \mathrm{layer}$ & 1361.89 & 92.5 & 2 \\
$\mathrm{O}_{2} / \mathrm{N}_{2}$ a.m. & 1518.65 & 106.15 & 2 \\
$\mathrm{O}_{2} / \mathrm{N}_{2}$ a.m. & 1699.44 & 126.35 & 2.4 \\
term. II & 1764.5 & 130.1 & 2 \\
$\mathrm{O}_{2} / \mathrm{N}_{2}$ a.m. & 1900.96 & 150.25 & 4 \\
$\mathrm{O}_{2} / \mathrm{N}_{2}$ a.m. & 2014.86 & 176.25 & 5.6 \\
$\mathrm{O}_{2} / \mathrm{N}_{2}$ a.m. & 2103.27 & 197.25 & 4.2 \\
$\mathrm{O}_{2} / \mathrm{N}_{2}$ a.m. & 2203.28 & 221.15 & 2 \\
$\mathrm{O}_{2} / \mathrm{N}_{2}$ a.m. & 2267.21 & 240.55 & 2.2 \\
$\mathrm{O}_{2} / \mathrm{N}_{2}$ a.m. & 2345.4 & 268.05 & 2 \\
$\mathrm{O}_{2} / \mathrm{N}_{2}$ a.m. & 2389.38 & 290.85 & 1.4 \\
$\mathrm{O}_{2} / \mathrm{N}_{2}$ a.m. & 2438.38 & 313.15 & 1.6 \\
$\mathrm{O}_{2} / \mathrm{N}_{2}$ a.m. & 2488.03 & 334.85 & 4 \\
\hline
\end{tabular}

the Vostok ${ }^{10} \mathrm{Be}$ age scale (Raisbeck et al., 1998). Frezzotti et al. (2005) found a value of $2.759 \mathrm{~cm}$-of-ice/yr from the Tambora volcanic horizon (1815 A.D.).

At Dome Fuji $A_{0}=2.913$ [2.979 \pm 0.184$] \mathrm{cm}$-of-ice/yr, i.e. the present-day accumulation rate is $5 \%$ higher than at Dome C. This value is about $5 \%$ less than the value of $3.11 \mathrm{~cm}$-ofice/yr used by Watanabe et al. (1999), but agrees very well with the value of $2.89 \mathrm{~cm}$-of-ice/yr obtained by Watanabe et al. (2003c) with a similar approach. From our study, the inferred average value is $2.675 \mathrm{~cm}$-of-ice/yr over recent millennia and $2.806 \mathrm{~cm}$-of-ice/yr over the last $7 \mathrm{kyr}$.

At Dome C, $\beta=0.0157$ [0.0156 \pm 0.0012$]$, and at Dome Fuji, $\beta=0.0147[0.0153 \pm 0.0031]$. Both these values are larger than the value of 0.0102 obtained using the saturation vapour pressure relationship, $\alpha=1 / 6.04 \mathrm{~K} / \% \circ$ and a factor of 0.63 for the surface temperature/inversion temperature relationship (Connolley, 1996). This value is consistent with the isotope-accumulation relationship obtained for the Vostok ice core in Antarctica (Parrenin et al., 2004), which is roughly equivalent to Eq. (6) with $\beta=0.0136 \pm 0.0024$. This means that until now, the glacial-interglacial amplitude of accumulation rate change has been underestimated. The difference for the Holocene-LGM amplitude reaches a factor of 1.4. Note that a very close value of 0.0152 for $\beta$ is also found in a recent review of present-day Antarctic surface data (Masson-Delmotte et al., 2007 ${ }^{7}$ ). Such a larger amplitude of accumulation changes can be obtained with the saturation vapour pressure relationship by increasing the amplitude of condensation temperature change by a factor of 1.5 .

\footnotetext{
${ }^{7}$ Masson-Delmotte, V., Shugui, H., Ekaykin, A., et al.: A review of Antarctic surface snow isotopic composition: traverse data, atmospheric circulation and isotopic modelling, in preparation, 2007.
}

For the top part of the Dome C ice core, the optimized model does not pass through all age markers within their confidence intervals (see the companion paper Parrenin et al. (2007) for more details). For this part, the thinning function is well constrained by the modelling, and we interpret this data-model difference as the fact that the accumulation rate cannot be deduced from the isotope content of ice with the simple relationship in Eq. (6). It is why we a posteriori modified the modelled accumulation rate to fit exactly with selected age markers in the top part. The corrected accumulation curve is shown in Fig. 3. As had already been found in Schwander et al. (2001), it seems the accumulation rate is underestimated during the early Holocene when deduced from the isotopic composition. Sensitivity tests show that, even when accounting for the source effects with the deuterium excess content of the ice, this discrepancy is not resolved. This decoupling between accumulation rate and isotopic content of ice during the last $20 \mathrm{kyr}$ had already been suggested for EDML by Landais et al. (2006) and for Law Dome by van Ommen et al. (2004).

\subsection{Reconstruction of basal conditions}

For Dome Fuji, the value of the most likely scenario for basal melting is $0.011 \mathrm{~mm} / \mathrm{yr}$, but this value is actually poorly constrained because the bottom of the first drilling is still more than $500 \mathrm{~m}$ above the bedrock (see Fig. 2). In any case, the basal melting is always less than $0.4 \mathrm{~mm} / \mathrm{yr}$, and there is a probability $\sim 90 \%$ that basal melting is $<0.2 \mathrm{~mm} / \mathrm{yr}$. Previous field temperature modelling had concluded that the temperature is at melting point at the bedrock interface (Saito et al., 2004), but with zero melting (Hondoh et al., 2002). We should note however that all modelling studies attempted 

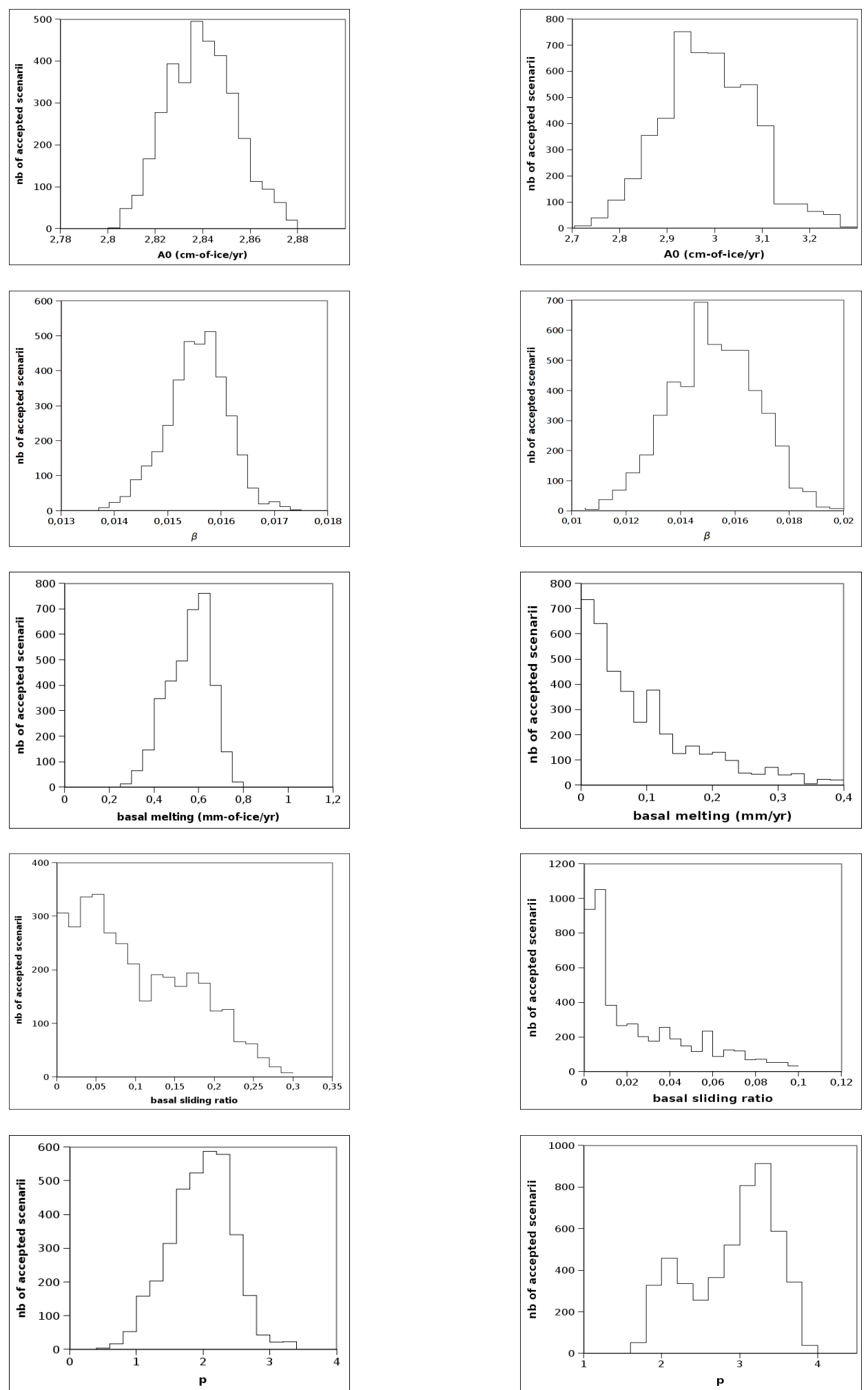

Fig. 2. Densities of probably for the poorly-known parameters of the glaciological dating model as reconstructed from the inverse method. Left column: Dome C. Right column: Dome Fuji. 


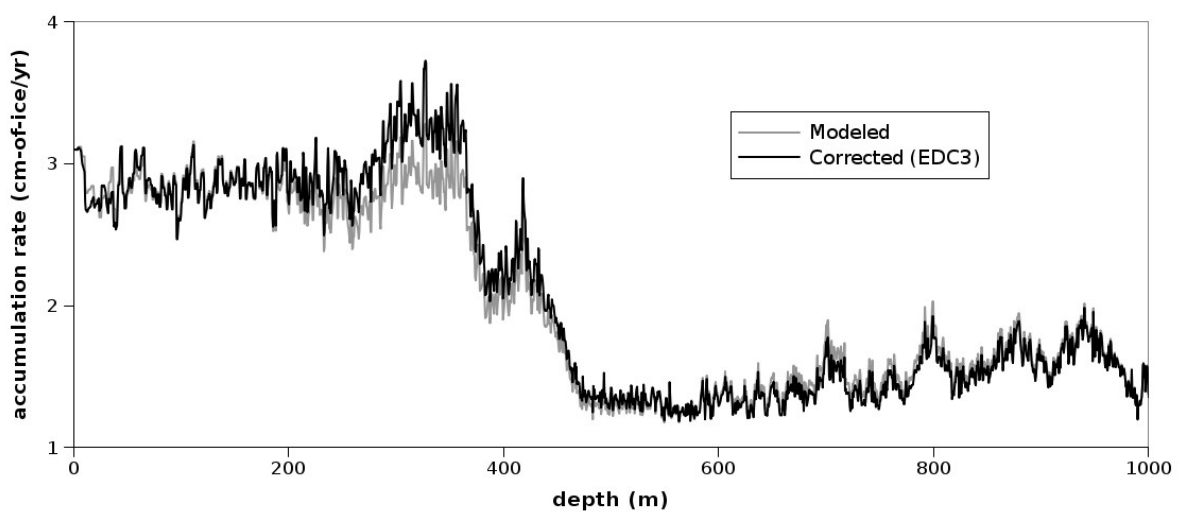

Fig. 3. Accumulation rates for the top part of the Dome $\mathrm{C}$ ice core, inferred from the accumulation model, or corrected in order to fit with the age markers.

so far (including the present one) are fundamentally limited because of their 1-D or flat representation of the bedrock around Dome Fuji. New temperature measurements that will be conducted in the second Dome Fuji borehole down to the bedrock will give a definitive answer to this problem.

Basal sliding at DF seems better constrained (see Fig. 2), and far smaller than at Dome $\mathrm{C}$. There is indeed a probability $\sim 90 \%$ that basal sliding is $<3 \%$. These estimates of basal melting and sliding at Dome Fuji should however be taken with caution, because they are based on a 1-D ice flow model, while complicated 3-D ice flow effects may exist at the base of the Dome Fuji drilling site.

For Dome $\mathrm{C}$, the most likely value of the basal melting is $0.66 \mathrm{~mm} / \mathrm{yr}$. The confidence interval $( \pm 2 \sigma)$ is $0.56 \pm 0.19 \mathrm{~mm} / \mathrm{yr}$, that is to say that the presence of basal melting is significant. This value is indeed better constrained than at Dome Fuji because we have age markers close to the bedrock. The fact that there is basal melting at Dome $\mathrm{C}$ is consistent with temperature profile measurements that suggest that the basal ice is at the melting point. It concords with the presence of water at the ice-bedrock interface as suggested by the seismic experiments conducted in the borehole (see Sect. 2.1). Consistent with this presence of basal melting, we found a high probability that basal sliding at Dome $\mathrm{C}$ is non negligible: there is $\sim 50 \%$ chance that this basal sliding is $>10 \%$.

\subsection{Reconstruction of the velocity profile}

The values of the $p$ parameter of the velocity profile reconstructed by the inverse method are 2.30 [1.97 \pm 0.93$]$ for Dome C and 3.71 [3.10 \pm 0.73 ] for Dome Fuji. These values are significantly smaller than the theoretical values $p \approx 9$ obtained in Sect. 2.2, meaning a more non-linear velocity profile.

As explained in Sect. 2.2, tests conducted with a fullStokes model under conditions where the SIA applies, even assuming anisotropic behaviour of the ice, confirmed very well the theoretical value deduced from Lliboutry's analytical development. We thus deduce that there are non SIA conditions affecting the flow at Dome $\mathrm{C}$ and Dome Fuji. In particular, we suggest that bedrock relief may play an important role. This highlights the need for 3-D local full-Stokes models to improve our understanding of ice flow around these drilling sites.

\subsection{Reconstruction of surface elevation}

The vertical velocity of ice at the surface $a-\frac{\partial H}{\partial t}$, the ice thickness and the surface elevation variations are illustrated in Fig. 4 for both Dome C and Dome Fuji.

Vertical velocity at the surface varies from $0.015 \mathrm{~m} / \mathrm{yr}$ for maximum glacial periods to $0.035 \mathrm{~m} / \mathrm{yr}$ for interglacial periods, that is to say there is more than a factor of two between glacial and interglacial values. Vertical velocity at the surface is on average more important at Dome Fuji, because of a higher accumulation rate.

The variations in surface elevation have an amplitude less than that of ice thickness, because a part of the ice thickness variations is compensated by the variations in bedrock elevation. Surface elevation change with respect to present varies from +40 to $+60 \mathrm{~m}$ for MIS5, 9 and 11 to $-120 \mathrm{~m}$ for maximum glacial periods.

Ice thickness change with respect to present varies from +50 to $+70 \mathrm{~m}$ for MIS5, 9 and 11 to -150 to $-160 \mathrm{~m}$ for maximum glacial periods. These values are in good agreement with those obtained by Ritz et al. (2001), though this work used an accumulation reconstruction with a reduced glacial-interglacial contrast. Hondoh et al. (2004) found a larger LGM-Holocene amplitude of around $200 \mathrm{~m}$.

This amplitude of around $110 \mathrm{~m}$ of Holocene-LGM surface elevation change gives an elevation correction of about $1^{\circ} \mathrm{C}$ when taking into account the temperature/surface elevation coefficient of $9^{\circ} \mathrm{C} / \mathrm{km}$ given by Krinner and Genthon 

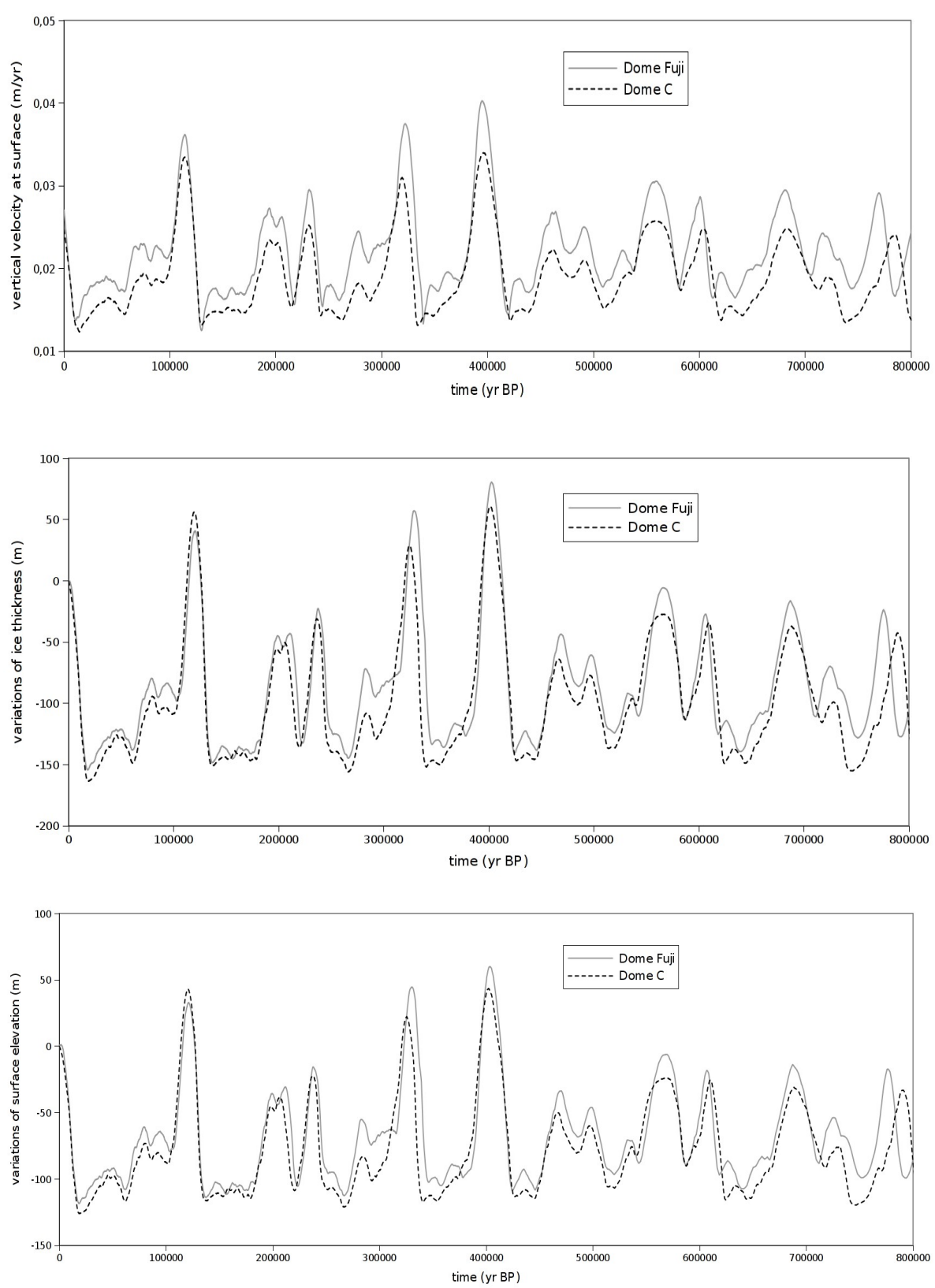

Fig. 4. Vertical velocity of ice at surface (top), variations in ice thickness (middle) and variations in surface elevation (bottom) simulated by the simplified elevation models applied for Dome C and Dome Fuji sites.

(1999). This correction increases the temperature change given by the isotope record, that is to say that the climatic temperature during the LGM is about $1^{\circ} \mathrm{C}$ colder than the temperature inferred from the isotope content.

\subsection{Thinning function and annual layer thickness}

The thinning function for the optimal scenario is illustrated in Fig. 5 for both Dome $\mathrm{C}$ and Dome Fuji. The general shape is slightly non-linear in both cases, due to the non-linearity in the velocity profile (see discussion in Sect. 4.3). The value tends to 0 for Dome Fuji because of a very small basal melting rate, whereas it tends to $5 \%$ for Dome $\mathrm{C}$ due to greater basal melting.

Another characteristic of these thinning functions is the presence of "bumps", corresponding to climatic periods. These bumps are due to variations in ice thickness over time. For example, the ice deposited during the last glacial maximum has encountered less thinning than in the case of a constant ice thickness. This is because the total vertical displacement of the glacial maximum layer with respect to the 

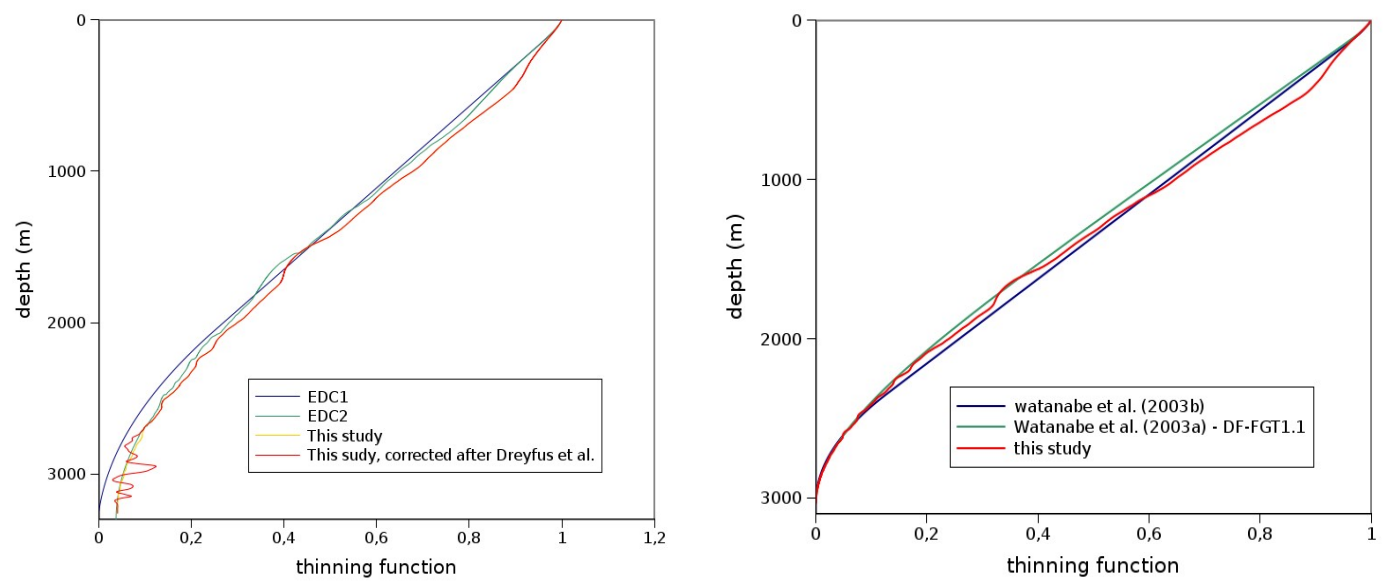

Fig. 5. Total thinning function in the deep drilling at Dome C (left) and Dome Fuji (right).

bedrock is less than its actual depth in the ice sheet. Conversely, the ice deposited during the last interglacial is more thinned because the ice thickness was large at that time. The presence of bumps in the thinning function has previously been suggested at Vostok (Parrenin et al., 2004), but as a consequence of spatial variations in ice thickness along a flow line. Here we show that temporal variations in the ice thickness also have an impact on the thinning function. In particular, our new estimates of total thinning at Dome $\mathrm{C}$ and Dome Fuji are larger than previous estimates for the last glacial period (Fig. 5).

The dependence of the thinning function on the ice thickness at the time of deposition may be used for the reconstruction of ice sheets in coastal areas during the past. Indeed, for a coastal drilling site such as Berkner Island, if the ice age and the accumulation rate at deposition are known with a sufficient degree of accuracy, the ice thickness at time of deposition can be deduced.

It is remarkable that such simple 1-D flow models are able to fit the age markers so well, and it implies that the flow conditions at these sites are quite simple to first order. This is particularly true for Dome $\mathrm{C}$ where the drilling was stopped within a few meters of the bedrock. There are, however, two noticeable exceptions to this good agreement between model and age markers for the Dome $\mathrm{C}$ core. In the depth interval 2700-3050 m, the glaciological model cannot fit the age markers obtained from the record of ${ }^{18} \mathrm{O}$ of atmospheric $\mathrm{O}_{2}$, and other evidences show that there are anomalies in the thinning function. It is why this modelled thinning function has been a posteriori corrected (see Dreyfus et al., 2007, for more details). The second interval is the extreme bottom part of the core, below the cold stages corresponding to Marine Isotope Stage 20, where our simple 1-D model does not capture the dominant physical processes. The origin and age of this basal ice is not yet clear.
Annual layer thickness for Dome C and Dome Fuji is illustrated in Fig. 6. It decreases from more than $3 \mathrm{~cm}$-of-ice for certain parts of the Holocene, to less than $0.1 \mathrm{~cm}$-of-ice for the bottom of the cores. This calculated annual layer thickness is in good agreement, for Dome Fuji, with annual layer identifications based on air bubbles and hydrates (Narita et al., 2003), except for one depth interval corresponding to the last interglacial around $120 \mathrm{kyr}$ BP.

\subsection{Age of Dome Fuji bottom ice}

Ice flow modelling makes it possible to estimate the age of the ice in the bottom part of the Dome Fuji deep drilling, where no age markers are yet available. In particular, the inverse method reconstructs a density of probability for the age at each depth, from which a confidence interval $( \pm 2 \sigma)$ can be calculated. Ice more than several millions years old is expected close to the ice-bedrock interface.

The past accumulation rates at DF before $350 \mathrm{kyr}$ BP have been estimated from the EDC deuterium data (see Sect. 2.3), and we do not expect uncertainties larger than 10-20\% coming from this reconstruction. Note however that the bottom age estimate is based on our simple 1-D ice flow model, and does not take into account complicated 3-D ice flow effects. For example, preliminary results suggest that ice layers are significantly inclined at the bottom of the new Dome Fuji drilling.

\section{Conclusions and perspectives}

In the present study, we have modelled ice flow at Dome $\mathrm{C}$ and Dome Fuji with a 1-D mechanical model with an analytical velocity profile, taking into account variations in ice thickness and deducing the accumulation rate from the isotopic content of the ice. The poorly constrained parameters of these accumulation and mechanical models have been 

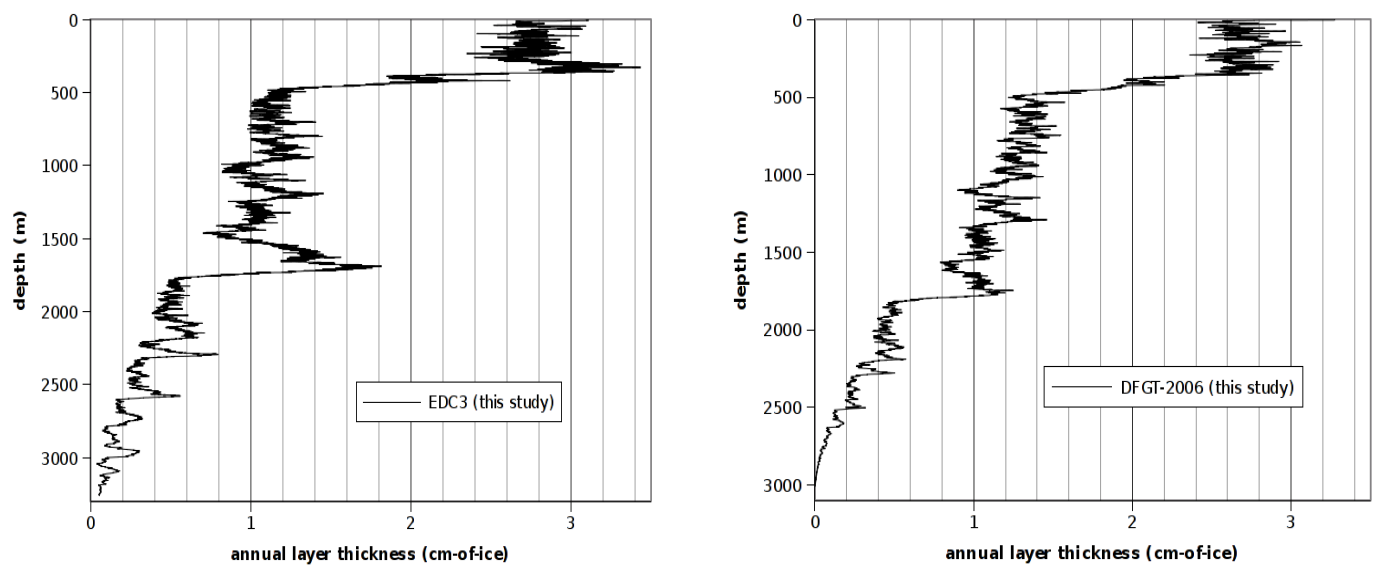

Fig. 6. Annual layer thickness at Dome C (left) and Dome Fuji (right).

tuned so that the resulting chronologies of each deep drilling fit some given independent age markers. We confirmed that glacial accumulation rates in central Antarctica prior to this study have been underestimated by the classical saturation vapour pressure relationship. We also show that at Dome C, there has been an excess of accumulation during the early Holocene that is not simply related to the isotopic content of the ice during this period. From a simplified ice sheet model, we reconstructed changes in surface and bedrock elevation, and we found, for both drilling sites, a LGM surface elevation $\sim 120 \mathrm{~m}$ lower, and a LGM ice thickness $\sim 160 \mathrm{~m}$ smaller than for the present. Moreover, we showed that past changes in ice thickness may be reconstructed from the analysis of an ice core, because they are imprinted in the depthage relationship. This exercise may help in reconstructing the ice sheet morphology during the past at coastal drilling sites such as Berkner is. We inferred a value of $0.56 \pm 0.19 \mathrm{~mm} / \mathrm{yr}$ for basal melting at Dome C. Finally, we suggest that the profile of vertical velocity is highly non-linear at both sites, which suggests complex ice flow effects, a consequence of the anisotropic behaviour of the ice and of the bedrock relief.

The accumulation reconstructions based on the isotopic content of the drilled ice now show their limit. An accurate estimate of past accumulation rates is indeed the basis for an accurate age scale, and new independent proxies are needed to improve ice core chronologies and interpretations at low accumulation sites.

A next step to improve the mechanical modelling is to take into account complex ice flow effects by using a local 3-D full-Stokes model. The use of such a model is, however, challenging in several respects. First, the heavy computation time makes it difficult to perform brute-force non-stationary ice flow simulations for the last hundreds of thousands of years. Only snapshots of the velocity field can be made. Second, the boundary conditions of such a 3-D model are not easy to determine: lateral conditions (velocity or stresses) or basal conditions (melting or sliding). Third, the mechani- cal behaviour of the ice depends upon its structural parameters (grain size and orientation), and is thus not homogeneous along an ice core (Durand et al., 2007). And fourth, the use of these models in conjunction with data (age markers and fabric data along the ice cores, surface elevation and velocity measurements, isochrone data, etc.) requires the development of complex identification methods.

\section{Appendix A}

\section{On ice flow models}

The velocity profile expressed in Eq. (1) with the $z$ coordinate, can also be expressed with the $\zeta$ coordinate as

$u_{\zeta}(\zeta)=-\frac{1}{H}\left[m+\left(a-\frac{\partial H}{\partial t}-m\right) \omega(\zeta)+\zeta \frac{\partial H}{\partial t}\right]$.

We should note at this stage that the formulations used in Salamatin et al. (2004) and Hondoh et al. (2004) are incomplete, because they remove the two terms depending on the temporal variations in $H$. These terms cancel when $\omega(\zeta)=\zeta$, i.e. in plug flow, but not when there is an internal deformation. The impact of this simplification on the age scale may be small, however.

Writing $\mu=\frac{m}{a-m}$, we can show easily that the thinning function has an analytical expression if $\mu$ is constant with time (which happens in particular when there is no basal melting):

$T(z)=\frac{\omega+\mu}{1+\mu}$,

which simply reduces, in the absence of basal melting, to $T(z)=\omega(\zeta)$.

The Lliboutry model in Eqs. (2) and (3) can be expressed in a different way:

$\omega(\zeta)=\zeta-\frac{1-s}{p+1}(1-\zeta)\left[1-(1-\zeta)^{p+1}\right]$. 
Salamatin et al. (2004) and Hondoh et al. (2004) used this kind of formulation.

In the Dansgaard-Johnsen model, the flux-shape function is written as the sum of a sliding term and a deformation term like in Eq. (2), with the deformation term given by:

$\omega_{D}(\zeta)=k\left[\frac{\zeta^{2}}{2 \zeta_{s}}+\sigma \frac{\zeta_{s}}{(2 \pi)^{2}} \cos \left(2 \pi \frac{\zeta}{\zeta_{s}}\right)\right] \quad$ if $\zeta<\zeta_{s}$,

$\omega_{D}(\zeta)=k\left(\zeta-\frac{\zeta_{s}}{2}\right) \quad$ if $\quad \zeta \geq \zeta_{s}$

with $\zeta_{s}=\frac{h}{H}, k=\frac{1}{1-\zeta_{s} / 2}$ and $0 \leq \sigma \leq 1$. The $\sigma$ parameter takes into account the special flow conditions close to ice divides, where shear stresses are negligible, leading to the so-called Raymond bumps (Raymond, 1983). The shape function for the horizontal velocity profile is thus given by:

$\omega_{D}^{\prime}(\zeta)=k\left[\frac{\zeta}{\zeta_{s}}-\frac{\sigma}{2 \pi} \sin \left(2 \pi \frac{\zeta}{\zeta_{s}}\right)\right] \quad$ if $\zeta<\zeta_{s}$,

$\omega_{D}^{\prime}(\zeta)=k$ if $\zeta \geq \zeta_{s}$,

Note that although the $\sigma$ parameter impacts the velocity profiles only in the bottom shear layer in this formulation, the Raymond bumps can be seen on the whole ice column (Conway et al., 1999). Raymond (1983) suggested a parabolic profile for $\omega$ (that is to say for the horizontal velocity). This parabolic profile corresponds to an exponent $p=0$ in the Lliboutry model.

\section{Appendix B}

\section{Smooth modification of the accumulation to fit given age markers}

Let us consider the modelled age scale $X^{M}(d)$ that is a function of the depth $d$. This modelled age is given by:

$X^{M}(d)=\int \frac{1}{a^{M}(z) T(z)} d z$,

where $a^{M}(d)$ is the modelled accumulation rate, and $T(d)$ is the modelled thinning function, at depth $d$.

We also have independent age markers $X_{i}$ for depths $d_{1}, \ldots$, $d_{n}$. We want to correct smoothly the accumulation record so that the ages at depth $d_{1}, \ldots, d_{n}$ agree with the age markers. For that, we define a correction coefficient $C(d)$ that is defined as a spline interpolant of $1, X_{1} / X^{M}\left(d_{1}\right), \ldots, X_{n} / X^{M}\left(d_{n}\right)$, 1 for depths $d_{0}, d_{1}, \ldots, d_{n}$ (where $d_{0}$ and $d_{n}$ are the depths where we start and stop the accumulation correction). The spline is a cubic spline with conditions of null first derivative for depths $d_{0}$ and $d_{n}$, or null second derivative for $d_{0}$ if $d_{0}=0 . C(d)$ is then equal to 1 for $d>d_{n}$ and $d<d_{0}$. This method ensures that $C(d)$ is continuous and derivable and that its derivative is continuous (i.e. $C$ is a $C^{1}$ function). Our corrected age scale $X^{C}(d)$ will be:

$X^{C}(d)=X^{M}(d) \times C(d)$
Now $X^{C}(d)$ has to be defined by the following:

$X^{C}(d)=\int \frac{1}{a^{C}(z) T(z)} d z$,

with $a^{C}(\mathrm{~d})$ being the corrected accumulation. Differentiating $X^{M}(d)$ and $X^{C}(d)$ leads to the following formula for the corrected accumulation:

$a^{C}(d)=\left(\frac{C(d)}{a^{M}(d)}+X^{M}(d) C^{\prime}(d) T(d)\right)^{-1}$.

Because $C(d)$ is $C^{1}, a^{C}(d)$ will be continuous, i.e. the correction of the accumulation will be smooth.

Acknowledgements. We thank E. Wolff, G. Krinner and D. Raynaud for helpful discussions, as well as two anonymous referees for their constructive comments. This work was funded by the French ANR projects MIDIGA and PICC. It is a contribution to the European Project for Ice Coring in Antarctica (EPICA), a joint European Science Foundation/European Commission scientific programme, funded by the EU (EPICA-MIS) and by national contributions from Belgium, Denmark, France, Germany, Italy, the Netherlands, Norway, Sweden, Switzerland and the UK. The main logistic support was provided by IPEV and PNRA (at Dome C) and AWI (at Dronning Maud Land). This is EPICA publication no. 172

Edited by: T. van Ommen

\section{References}

Andersen, K. K., Svensson, A., Johnsen, S. J., Rasmussen, S. O., Bigler, M., Röthlisberger, R., Ruth, U., Siggaard-Andersen, M.-L., Steffensen, J. P., Dahl-Jensen, D., Vinther, B. M., and Clausen, H. B: The Greenland Ice Core Chronology 2005, 1542 kyr. Part 1: Constructing the time scale, Quat. Sci. Rev., 25, 3246-3257, 2006.

Bassinot, F. C., Labeyrie, L. D., Vincent, E., Quidelleur, X., Shackleton, N. J., and Lancelot, Y: The astronomical theory of climate and the age of the Brunhes-Matuyama magnetic reversal, Earth Planet. Sci. Lett., 126(1-3), 91-108, 1994.

Bintanja, R., Van de Wal, R. S., and Oerlemans, J: Modelled atmospheric temperatures and global sea levels over the past million years, Nature, 437, 125-128, 2005.

Castellano, E., Becagli, S., Hansson, M., Hutterli, M., Petit, J. R., Rampino, M. R., Severi, M., Steffensen, J. P., Traversi, R., and Udisti, R: Holocene volcanic history as recorded in the sulfate stratigraphy of the European Project for Ice Coring in Antarctica Dome C (EDC96) ice core, J. Geophys. Res., 116, D06114, doi:10.1029/2004JD005259, 2005.

Connolley, W. M: The Antarctic temperature inversion, Int. J. Climatol., 16, 1333-1342, 1996.

Conway, H., Hall, B. L., Denton, G. H., Gades, A. M., and Waddington, E. D: Past and Future Grounding-Line Retreat of the West Antarctic Ice Sheet, Science, 286, 280-283, 1999.

Dreyfus, G., Parrenin, F., Lemieux-Dudon, B., Durand, G., MassonDelmotte, V., Jouzel, J., Barnola, J.-M., Panno, L., Spahni, R., Tisserand, A., Siegenthaler, U., and Leuenberger, M: Anomalous flow below $2700 \mathrm{~m}$ in the EPICA Dome $\mathrm{C}$ ice core detected using 
$\delta^{18} \mathrm{O}$ of atmospheric oxygen measurements, Clim. Past Discuss., 3, 63-93, 2007,

http://www.clim-past-discuss.net/3/63/2007/.

Durand, G., Gillet-Chaulet, F., Svensson, A., Gagliardini, O., Kipfstuhl, S., Meyssonnier, J., Parrenin, F., Duval, P., and DahlJensen, D: Change of the ice rheology with climatic transitions - implication on ice flow modelling and dating of the EPICA Dome C core, Clim. Past, 3, 155-167, 2007, http://www.clim-past.net/3/155/2007/.

EPICA community members: 8 glacial cycles from an Antarctic ice core, Nature, 429, 623-628, 2004.

Forieri, A., Zuccoli, L., Bini, A., Zirizzotti, A., Rémy, F., and Tabacco, I. E: New bedrock map of Dome C, Antarctica, and morphostructural interpretation of the area, Ann. Glaciol., 39, 321-325, 2004.

Frezzotti, M., Pourchet, M., Flora, O., Gandolfi, S., Gay, M., Urbini, S., Vincent, C., Becagli, S., Gragnani, R., Proposito, M., Severi, M., Traversi, R., Udisti, R., and Fily, M: Spatial and temporal variability of snow accumulation in East Antarctica from traverse data, J. Glaciol., 51(172), 113-124, 2005.

Fujita, S., Kawada, K., and Fujii, Y: Glaciological data collected by the 37th JapaneseAntarctic Research Expedition during 19961997, Data Reports Glaciology, 27, JARE, 1998.

Fujita, S., Maeno, H., Uratsuka, S., Furukawa, T., Mae, S., Fujii, Y., and Watanabe, $\mathrm{O}$ : Nature of radio-echo layering in the Antarctic ice sheet detected by a two-frequency experiment, J. Geophys. Res., 104(B6), 13 013-13 024, 1999.

Fujita, S., Maeno, H., and Matsuoka, K: Radio wave depolarization and scattering within ice sheets: A matrix based model to link radar and ice core measurements and its application, J. Glaciol., 52(178), 407-424, 2006.

Gillet-Chaulet, F: Modélisation de l'écoulement de la glace polaire anisotrope et premières applications au forage de Dôme $C, \mathrm{PhD}$ Thesis, Université Joseph Fourier, Grenoble, France, 2006.

Hondoh, T., Shoji, H., Watanabe, O., Salamatin, A. N., and Lipenkov, V. Y.: Depth-age scale and temperature prediction at Dome Fuji station, East Antarctica, Ann. Glaciol., 35, 384-390, 2002.

Hondoh, T., Shoji, H., Watanabe, O., Tsyganova, E., Salamatin, A. N., and Lipenkov, W. Y.: Average time scale for Dome Fuji ice core, East Antarctica, Polar Meteorology and Glaciology, 18, 118, 2004.

Johnsen, S. J. and Dansgaard, W: On flow model dating of stable isotope records from Greenland ice cores, in: The Last Deglaciation: Absolute and Radiocarbon Chronologies, edited by: Bard, E., and Broecker, W., Springler Verlag, Berlin Heidelberg, 1992.

Johnsen, S. J., Dahl-Jensen, D., Dansgaard, W., and Gundestrup, N. S: Greenland temperatures derived from GRIP bore hole temperature and ice core isotope profiles, Tellus, 47b(5), 624-629, 1995.

Johnsen, S., Dahl-Jensen, D., Gundestrup, N., Steffensen, J., Clausen, H., Miller, H., Masson-Delmotte, V., Sveinbjornsdottir, A. and White, J: Oxygen isotope and palaeotemperature records from six Greenland ice-core stations: Camp Century, Dye-3, GRIP, GISP2, Renland and NorthGRIP, J. Quat. Sci., 16, 299307,2001

Kawamura, K., Parrenin, F., Lisiecki, L., Uemura, R., Vimeux, F., Severinghaus, J. P., Hutterli, M. A., Nakazawa, T., Aoki, S., Jouzel, J., Raymo, M. E., Matsumoto, K., Nakata, H., Mo- toyama, H., Fujita, S., Azuma, K., Fujii, Y., and Watanabe, O.: Northern Hemisphere forcing of climatic cycles in Antarctica over the past 360,000 years, Nature, in press, 2007.

Krinner, G. and Genthon, C: Altitude dependence of the surface climate over the ice sheets, Geophys. Res. Lett., 26, 2227-2230, 1999.

Landais, A., Barnola, J., Kawamura, K., Caillon, N., Delmotte, M., van Ommen, T., Dreyfus, G., Jouzel, J., Masson-Delmotte, V., Minster, B., Freitag, J., Leuenberger, M., Schwander, J., Huber, C., Etheridge, D., and Morgan, V: Firn-air ${ }^{15} \mathrm{~N}$ in modern polar sites and glacial-interglacial ice: a model-data mismatch during glacial periods in Antarctica?, Quat. Sci. Rev., 25(1-2), 49-62, 2005.

Lhomme, N: Modelling water isotopes in polar ice sheets, $\mathrm{PhD}$ thesis, Université Joseph Fourier, Grenoble, 2004.

Lisiecki, L. E. and Raymo, M. E: A Plio-Pleistocene Stack of 57 Globally Distributed Benthic $\delta^{18} \mathrm{O}$ Records, Paleoceanography, 20(1), PA1003, 2005.

Lliboutry, L.: A critical review of analytical approximate solutions for steady state velocities and temperature in cold ice sheets, $\mathrm{Z}$. Gletscherkd. Glacialgeol., 15(2), 135-148, 1979.

Lliboutry, L. and Duval, P: Various isotropic and anisotropic ices found in glacier and polar ice caps and their corresponding rheologies, Ann. Geophys., 3(2), 207-224, 1985.

Lorius, C. and Merlivat, L: Distribution of mean surface stable isotope values in east Antarctica. Observed changes with depth in a coastal area, in: Isotopes and impurities in snow and ice, Proceedings of the grenoble symposium Aug/Sep 1975, 118, IAHS Publication, IAHS, Vienna, 1977.

Loulergue, L., Parrenin, F., Blunier, T., Barnola, J.-M., Spahni, R., Schilt, A., Raisbeck, G., and Chappellaz, J: New constraints on the gas age-ice age difference along the EPICA ice cores, 0-50 kyr, Clim. Past Discuss., 3, 435-467, 2007,

http://www.clim-past-discuss.net/3/435/2007/.

Narcisi, B., Petit, J.-R., and Tiepolo, M: A volcanic marker (92 kyr) for dating deep East Antarctic cores, Quat. Sci. Rev., 25, 26822687, 2006.

Narita, H., Azuma, N., Hondoh, T., Hori, A., Hiramatsu, T., FujiiMiyamoto, M., Satow, K., Shoji, H., and Watanabe, O: Estimation of annual layer thickness from stratigraphical analysis of dome fuji deep ice core (scientific paper), Memoirs of National Institute of Polar Research, Special issue, 57, 38-45, 2003.

Parrenin, F., Jouzel, J., Waelbroeck, C., Ritz, C., and Barnola, J.M: Dating the Vostok ice core by an inverse method, J. Geophys. Res., 106(D23), 31 837-31 851, 2001.

Parrenin, F., Rémy, F., Ritz, C., Siegert, M., and Jouzel, J: New modelling of the Vostok ice flow line and implication for the glaciological chronology of the Vostok ice core, J. Geophys. Res., 109, D20102, doi:10.1029/2004JD004561, 2004.

Parrenin, F., Hindmarsh, R., and Rémy, F: Analytical solutions for the effect of topography, accumulation rate and lateral flow divergence on isochrone layer geometry, J. Glaciol., 52(177), 191202, 2006.

Parrenin, F., Barnola, J.-M., Beer, J., Blunier, T., Castellano, E., Chappellaz, J., Dreyfus, G., Fischer, H., Fujita, S., Jouzel, J., Kawamura, K., Lemieux-Dudon, B., Loulergue, L., MassonDelmotte, V., Narcisi, B., Petit, J.-R., Raisbeck, G., Raynaud, D., Ruth, U., Schwander, J., Severi, M., Spahni, R., Steffensen, J. P., Svensson, A., Udisti, R., Waelbroeck, C., and Wolff, E: The 
EDC3 chronology for the EPICA Dome C ice core, Clim. Past Discuss., 3, 575-606, 2007,

http://www.clim-past-discuss.net/3/575/2007/.

Raisbeck, G. M., Yiou, F., Bard, E., Dollfus, D., Jouzel, J., and Petit, J. R: Absolute dating of the last 7000 years of the Vostok ice core using ${ }^{10} \mathrm{Be}$, Mineral. Mag., 62A, 1228, 1998.

Raisbeck, G. M., Yiou, F., Cattani, O., and Jouzel, J: ${ }^{10}$ Be evidence for the Matuyama-Brunhes geomagnetic reversal in the EPICA Dome C ice core, Nature, 444(7115), 82-84, 2006.

Raisbeck, G., Yiou, F., Jouzel, J., and Stocker, T.: Direct NorthSouth synchronization of abrupt climate change record in ice cores using beryllium 10, Clim. Past Discuss., 3, 755-769, 2007, http://www.clim-past-discuss.net/3/755/2007/.

Rasmussen, S. O., Andersen, K. K., Svensson, A. M., Steffensen, J. P., Vinther, B. M., Clausen, H. B., Siggaard-Andersen, M.L., Johnsen, S. J., Larsen, L. B., Dahl-Jensen, D., Bigler, M., Rothlisberger, R., Fischer, H., Goto-Azuma, K., Hansson, M. E., and Ruth, U: A new Greenland ice core chronology for the last glacial termination, J. Geophys. Res., 111, D06102, doi:10.1029/2005JD006079, 2006.

Raymond, C. F: Deformation in the vicinity of ice divides, J. Glaciol., 29(103), 357-373, 1983.

Ritz, C.: Interpretation of the temperature profile measured at Vostok, East Antarctica, Ann. Glaciol., 12, 138-144, 1989.

Ritz, C., Rommelaere, V.. and Dumas, C: Modeling the evolution of Antarctic ice sheet over the last 420,000 years: implications for altitude changes in the Vostok region, J. Geophys. Res., 106(D23), 31 943-31 964, 2001.

Rémy, F. and Tabacco, I: Bedrock features and ice flow near the EPICA ice core site (Dome C, Antarctica), Geophys. Res. Lett., 27(3), 405-408, 2000.

Rémy, F., Shaeffer, P., and Legrésy, B: Ice flow pysical processes derived from the ERS-1 high-resolution map of the Antarctica and Greenland ice sheets, Geophys. J. Int., 139, 645-656, 1999.

Saito, F. and Abe-Ouchi, A: Thermal structure of Dome Fuji and east Dronning Maud Land, Antarctica, simulated by a threedimensional ice-sheet model, Ann. Glaciol., 39, 433-438, 2002.

Salamatin, A. N. and Ritz, C: A simplified multi-scale model for predicting climatic variations of the ice-sheet suface elevation in central Antarctica, Ann. Glaciol., 23, 28-35, 1996.

Salamatin, A. N., Tsiganova, E. A., Lipenkov, V. Y., and Petit, J. R: Vostok (Antarctica) ice-core time scale from datings of different origins, Ann. Glaciol., 39, 283-292, 2004.

Schwander, J., Jouzel, J., Hammer, C. U., Petit, J.-R., Udisti, R., and Wolff, E: A tentative chronology for the EPICA Dome Concordia ice core, Geophys. Res. Lett., 28(22), 4243-4246, 2001.
Stenni, B., Jouzel, J., Masson-Delmotte, V., Rothlisberger, R., Castellano, E., Cattani, O., Falourd, S., Johnsen, S., Longinelli, A., Sachs, J., Selmo, E., Souchez, R., Steffensen, J., and Udisti, R: A late-glacial high-resolution site and source temperature record derived from the EPICA Dome $\mathrm{C}$ isotope records (East Antarctica), Earth. Planet. Sci. Lett., 217, 183-195, 2003.

Svensson, A., Andersen, K. K., Bigler, M., Clausen, H. B., DahlJensen, D., Davies, S. M., Johnsen, S. J., Muscheler, R., Rasmussen, S. O., Röthlisberger, R., Steffensen, J. P., and Vinther, B. M: The Greenland Ice Core Chronology 2005, 15-42 kyr. Part 2: Comparison to other records, Quat. Sci. Rev., 25, 3258-3267, 2006.

Tabacco, I. E., Passerini, A., Corbelli, F., and Gorman, M: Determination of the surface and bed topography at Dome C, East Antarctica, J. Glaciol., 44, 185-191, 1998.

Thorsteinsson, T., Kipfstuhl, J., and Miller, H: Textures and fabrics in the GRIP ice core, J. Geophys. Res., 102(C12), 26583 26600, 1997.

van Ommen, T., Morgan, V., and Curran, M: Deglacial and Holocene changes in accumulation at Law Dome, East Antarctica, Ann. Glaciol., 39, 359-365, 2004.

Vimeux, F., Cuffey, K., Jouzel, J., Stievenard, M., and Petit, J. R: New Insights into Southern Hemisphere temperature changes from Vostok ice cores using deuterium excess correction, Earth Planet. Sci. Lett., 203, 829-843, 2002.

Vittuari, L., Vincent, C., Frezzotti, M., Mancini, F., Gandolfi, S., Bitelli, G., and Capra, A: Space geodesy as a tool for measuring ice surface velocity in the Dome $\mathrm{C}$ region and along the ITASE traverse, Ann. Glaciol., 39, 402-408, 2004.

Watanabe, O., Kamiyama, K., Motoyama, H., Fujii, Y., Shoji, H., and Satow, K: The paleoclimate record in the ice core at Dome Fuji station, East Antarctica, Ann. Glaciol., 29, 176-178, 1999.

Watanabe, O., Jouzel, J., Johnsen, S., Parrenin, F., Shoji, H., and Yoshida, N: Homogeneous climate variability across East Antarctica over the past three glacial cycles, Nature, 422, 509512, 2003a.

Watanabe, O., Kamiyama, K., Motoyama, H., Fujii, Y., Igarashi, M., Furukawa, T., Goto-Azuma, K., Saito, T., Kanamori, S., Kanamori, N., Yoshida, N., and Uemura, R: General tendencies of stable isotopes and major chemical constituents of the Dome Fuji deep ice core, Memoirs of National Institute of Polar Research, Special issue, 57, 1-24, 2003 b.

Watanabe, O., Shoji, H., Satow, K., Motoyama, H., Fujii, Y., Narita, H., and Aoki, S: Dating of the Dome Fuji, Antarctica deep ice core, Memoirs of National Institute of Polar Research, Special issue, 57, 25-37, 2003c. 